\title{
Possible Health Hazard due to Effect of Utilization of Waste as Animal Feed
}

\author{
Ramchandra Ramteke $^{1 *}$, M. K. Gendley ${ }^{1}$, Raina Doneria ${ }^{1}$ and D. K. Jolhe ${ }^{2}$ \\ ${ }^{1}$ Department of Animal Nutrition, ${ }^{2}$ Department of Veterinary Pathology, College of Veterinary \\ Science and A.H, Anjora Durg.C.G.K.V., C.G, India \\ *Corresponding author
}

\section{Keywords}

Contaminants, Toxins foods and feeds

\section{Article Info}

Accepted:

17 June 2020

Available Online:

10 July 2020

\begin{abstract}
A B S T R A C T
In the intensive livestock production systems, with decrease in grazing land and intensification of agriculture, the animal feeds are supplemented with by-product of animal origin which are most likely to be contaminated with pesticides, dioxins, radionuclide, heavy metals, bacterial, fungal /mycotoxin contaminants etc., which may, market, it is the need of the hour to produce the livestock products free from contaminants. The feeds and fodders are to be cultivated in lands, which are devoid of heavy metals, radionuclide, industrial wastes, dioxins and other contaminants. The feeds are to be safeguarded from bacterial and fungal contamination from the time of harvest till the animals consume them otherwise chances of heavy health hazard to the human population through consumption of livestock products. As the contaminants can enter the food chain at any stage of livestock production system, a collective and concerted effort is required from agriculture, animal husbandry, feed Industry, animal production industry and food industry experts to give quality and safe foods to the consumers.
\end{abstract}

\section{Introduction}

The global food system is experiencing profound changes in consumption patterns, especially in the increasing demand for livestock products, leading to worldwide growth in intensive livestock production. In turn, there is an increasing need for adequate feed materials which need to be wholesome and safe for the animal as well as free of undesirable or toxic substances (Figure 1) that could compromise the quality and safety of animal-derived foods (Fink-Gremmels, 2012; Sharma et al., 2015).
Following the paradigm of One Health concept for human and animal populations, as a joint initiative between FAO, WHO and OIE and the objectives of an integrated food safety control system from farm to table, risk assessment methodologies have recently been amended, presenting now an integrated approach of the animal exposure and risk assessment, and a quantification of human exposure from animal-derived foods such as milk, meat and eggs, taking into account typical consumption patterns. The latter refers to the specific exposure of individual age groups (such as small children) and particular consumer preferences. These exposure data 
are compared with the Health-based guidance levels to complete the risk characterization (Dorne and Fink-Gremmels., 2013).

\section{Biological hazards in feed}

The most common biological hazards are zoonotic bacterial pathogens that enter the food chain via contaminated feeds and poor hygienic conditions at the farm level. The animal may experience clinical disease conditions, but in many cases remain a silent carrier of such pathogens (such as Campylobacter). When hygienic barriers are incomplete during slaughter and processing, the pathogen is transferred to meat, where they can proliferate under certain conditions. Eggs can be infected by horizontal transmission of pathogens in layer units and milk may be contaminated by mastitis pathogens prior or during the milking process.

Typical examples for such zoonotic pathogens are Campylobacter spp. in poultry, Salmonella spp., E. coli O157, Enterococci, and Staphylococcus spp. (Crump et al., 2002). Poor hygienic conditions at the farm level and raw materials used in feed manufacturing can be a source for the introduction of salmonella into the food chain. Feedstuffs and poultry feeds are contaminated by Enterococci and, to a lesser extent, by $E$. coli, thus leading to their introduction in the farm environment.

Silage is the most common source of Listeria monocytogenes on a farm (Czuprynski, 2005). In addition to bacteria, animal feeds can be contaminated with prions, the infectious agent associated with Bovine Spongiform Encephalopathy (BSE). The prevalence of these prions is currently declining worldwide. Other microbiological hazards and a detailed global survey on food borne diseases is presented in a recent WHO publication (Havelaar et al., 2015).

\section{Chemical hazards in feed}

Potential contaminants in feedstuffs include residues of persistent pesticides, brominated compounds or other environmental contaminants such as the polychlorinated biphenyls (PCBs), and dioxins as well as heavy metals including mercury, lead, or cadmium and natural toxins, such as mycotoxins. Feeds may also contain intentionally applied veterinary drugs, such as coccidiostats and antimicrobial growth promotors. Considering the recent concerns about the global emergence of antimicrobial resistance, antimicrobial growth promotors are banned in many regions (such as Europe) already since 2006 and phasing out strategies have been recommended to all countries by WHO in their recent documents on combating antimicrobial resistance.

\section{Pesticides}

Different kinds of pesticides are commonly used in agriculture for various purposes. Among those, organophosphates, pyrethroids and carbamates are comparatively rapidly degraded and consequently found in lesser amounts in feed and food, while persistent organochlorine pesticides (POPs) and even banned pesticides such as dichlorodiphenyltrichloroethane (DDT), aldrin, dieldrin, endrin, heptachlor, and hexachlorobenzene (HCB) may still be present as undesirable chemical residues in animal feed due to their low bio-degradability. Being one of the typical endpoints of the trophic food chain, milk is of special concern, because it is consumed often in high amounts relative to the body weight by children. Subsequently dairy milk has been used as an indicator of environmentally persistent organic micropollutants, such as organochlorine (OC) pesticides. Due to their lipophilic properties, pesticides are stored in fat-rich tissues, forming undesirable residues in meat and may 
be subsequently translocated and excreted through milk fat. Organophosphate pesticides are less lipophilic, and less persistent in animal tissues, but may cause clinical intoxications in animals. At the global level, the environmental burden of most pesticides is decreasing with the exception of dioxins, which remain of concern as important contaminants in the food chain (Havelaar et al., 2015, WHO Global Survey). In our recent study (Sharma et al., 2016), levels of pesticide residues (organochlorine, organophosphates and synthetic pyrethroids) were found to be below the detection limit $(0.01 \mathrm{mg} / \mathrm{kg})$ in analyzed fodder samples of semi arid region of Rajasthan, India.

\section{Dioxins}

Dioxins are the by-products of various industrial processes and are commonly regarded as highly toxic environmental pollutants. The term dioxin refers to polychlorinated dibenzo-p-dioxins (PCDDs), polychlorinated biphenyls (PCBs) and polychlorinated dibenzofurans (PCDFs). Livestock can be exposed to dioxins following the deposition of airborne dioxins onto plant and soil surfaces, and subsequent ingestion of this contaminated vegetation and soil. Dioxins accumulate in fatty tissues and consumption of animal-derived products is among the most predominant exposure routes for humans. As a result of bio-accumulation, these compounds have the potential to biomagnify in the food chain (EFSA, 2015).

\section{Heavy metals contamination}

Toxic heavy metals (cadmium, lead and mercury) and other chemical elements (arsenic, chromium, copper and zinc) occur naturally in the environment, but industrial processes may increase their concentration in distinct geographic regions, leading to their accumulation in plants that are consumed by animals or harvested as feed (Fink-Gremmels, 2012). Subsequently, the ubiquitous presence of some metal pollutants, especially cadmium (Cd), chromium (Cr), arsenic (As), nickel $(\mathrm{Ni})$, mercury $(\mathrm{Hg})$ and lead $(\mathrm{Pb})$, facilitates their bio-accumulation, leading to elevated levels in certain animal tissues and to a potential public health hazards. The heavy metals of major concern in the food chain are cadmium, mercury and lead. Cadmium specially accumulates in the liver and kidney of animals but its carry-over to milk is very low or negligible. Animals encounter lead from the soil that contained the leakage of acid-batteries. An increased exposure rate may result also from pastures near factories producing lead wire or pipes, as well as from effluents of metal recycling and foundries. Likewise to cadmium, milk rarely contains lead residues.

Mercury is one of the most highly bioconcentrated neuro-toxicants in the environment. It is toxic to all animal species and affects the central nerve system after conversion into its methylated forms (Clifton, 2007). Mercury occurs in the environment in several forms: Alkyl mercury compounds tend to accumulate in skeletal muscles and brain, whereas aryl compounds and inorganic mercury salts accumulate in liver and kidneys (Kan and Meijer., 2007). The consumption of fish is by far the most significant source of food related mercury exposure in humans, although plants and livestock products may also contain mercury residues.

\section{Natural toxins}

Among the natural toxins, mycotoxins have a significant impact on human and animal health, resulting also in economic and international trade implications (MarroquínCardona et al., 2014). Most mycotoxins are rather stable and resist common feed processing procedures. The most prominent 
example is aflatoxin B1, which is considered as one of the strongest liver carcinogens in humans as well as in all animal species tested. It occurs in a broad variety of food and feed materials. Aflatoxin B1 does not accumulate in animal tissues, but gets converted in the liver to aflatoxin M1, which is excreted in milk. Worldwide the regulatory authorities are aiming to protect human and particularly infants from exposure to aflatoxin B1 and M1. Animal-derived products, such as poultry meat and porcine kidneys and tissues are regularly found to contain residual amounts of ochratoxin A, which might be implicated in the prevalence of renal diseases and even cancer in humans. Another potentially carcinogenic mycotoxin is fumonisin $\mathrm{B} 1$, the most toxic derivative of the class of fumonisins, produced by Fusarium species. Direct exposure to humans particularly in regions with a traditional high consumption of yellow corn (maize) remains of concern, while exposure via animal-derived products is negligible. At the global level the increase of Fusarium toxins in food and feed materials is of increasing concern, and cause significant losses in animal production and impair animal health and productivity.

\section{Veterinary drug residues}

Veterinary drug residues may be found in animal products as a result of their use in animals without taking into account the prescribed withdrawal (drug withholding) times. As all veterinary drugs have passed a pre-marketing approval procedure excluding severe health concerns, such as mutagenic and carcinogenic effects, the public health risk associated with residues remains low. Moreover, the carryover of veterinary drugs in feed ingredients during feed production may result in unexpected residues in animal tissues, when the following feed batch is used for another animal species, as for examples demonstrated for coccidiostats. This undesirable carryover poses as serious animal health risk.

There is some evidence to suggest that antibiotics used in the fermentation process to control microbiological contamination during the processing of grains for ethanol production may concentrate in dried distiller's grains with soluble (DDGS) and result in an undesirable exposure of animals.

Of recent concern is the use of antibiotic in livestock production, which has been associated with the prevalence of antibiotic resistance and the potential transmission of resistant bacterial strains for animals to humans. This concerns in particular zoonotic pathogens such as Salmonella, Campylobacter, Enterococci and Staphylococcus aureus which might be present in food of animal origin (Chang et al., 2014; Landers et al., 2012).

\section{Radionuclides and nano materials}

Radionuclides including caesium-134, caesium-137, strontium-90 and iodine-131 present in animal feed and forages may get transferred to edible products. Major sources are contaminated soil, water and forage. Transfer of radioiodine to milk, radiostrontium to bone, and radio-caesium to milk, eggs and meat has been demonstrated (FAO/WHO, 2013). Recently, the possibility of migration substances from packaging material, nano-plastics which might be present in animal feed is discussed as an emerging risk and requires further surveillance and monitoring. resistant bacterial strains for animals to humans.

\section{Physical hazards}

Various physical agents viz. iron nails, small pebbles, metal fragments, screws, rivets, machine filings, glass shards, wood splinters, 
stones, insulation paints, plastic fragments, personal effects (jewellery, buttons, nail fragments, nail varnish), hair, dust and dirt sharp objects etc. while consumed by the livestock, can exert a significant impact on animal health and production depending on material, form and size. Such agents are not transferred to the animal tissue and thus do not directly affect the food safety.

\section{Animal feed safety regulations}

International standards, guidelines and recommendations on food quality and safety are being regularly issued by $\mathrm{FAO} / \mathrm{WHO}$
Codex Alimentarius Commission and also by the EU Commission. The objective of the Codex Code of Practice on good animal feeding (CAC/RCP 54-2004) aims to ensure the safety of food for human consumption (Figure 2) through adherence to good animal feeding practice at the farm level and good manufacturing practices (GMPs) during the procurement, handling, storage, processing and distribution of animal feed and feed ingredients for food-producing animals. Codex Alimentarius Standards are recognized in the WTO-SPS-Agreement (Sanitary and Phytosanitary Measures) as the benchmark for food safety.

Fig.1 Sources of contamination in animal feed

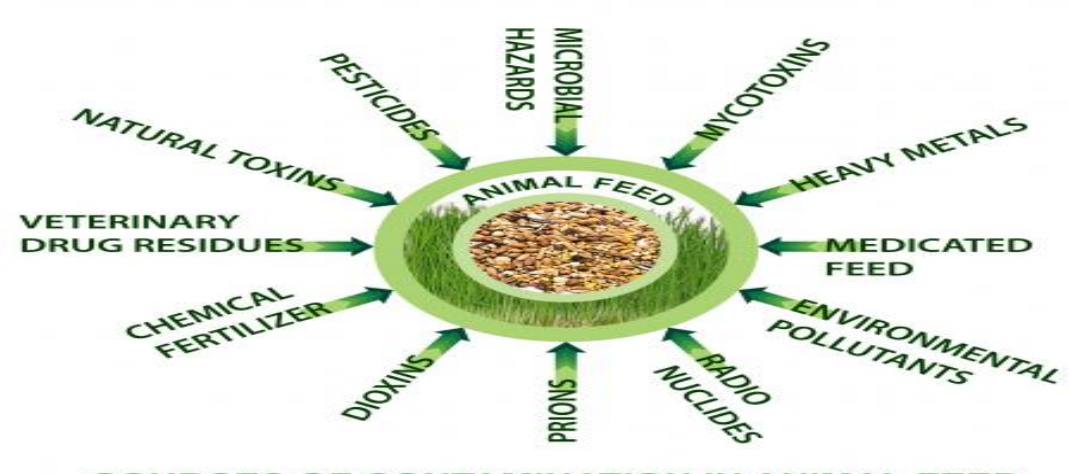

SOURCES OF CONTAMINATION IN ANIMAL FEED

Fig.2 Safe animal feed to safeguard human health

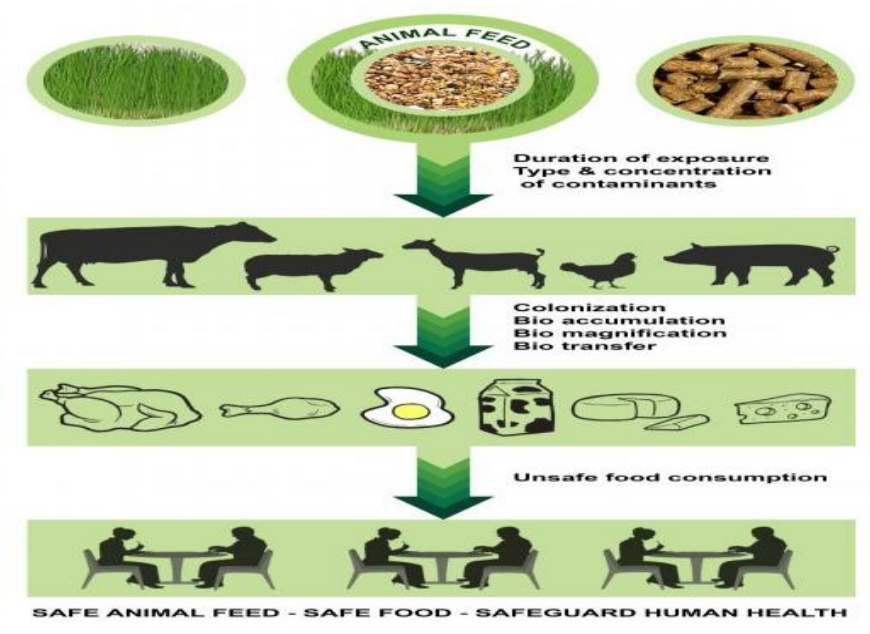


In consideration of these guidance the following suggestions for improving feed safety can be presented.

\section{Some suggestions for improving feed safety}

Each country should adopt the FAO/WHO Codex Alimentarius standards for producing safe feed, and national guidelines should be issued in line with these guidance documents.

Awareness and capacity building programmes need to be implemented for feed manufacturers and livestock farmers.

Hazard Analysis and Critical Control Points (HACCP)protocols need to be established for the feed industry to guarantee compliance with good manufacturing practice.

Regular screening of feed ingredients and final feed for various undesirable substances by national governmental institutions should be implemented.

\section{Future research}

Identification and prioritization of potential hazards for animal feed in specific agroclimatic zone.

Development of simple and rapid screening methods for laboratories to manage large number of samples.

Exposure assessment through the collation of large sets of data on the occurrence of feed contaminants at the global level

Assessment of undetected or emerging hazards from newer feedstuffs viz. biofuel by-products, insects, aquatic plants and marine products, which may be used as feed materials. The assessment can support the increasing need for safe feed materials.

In conclusion changing food habits and food pattern requires a thorough surveillance to establish SAFE FOOD chain from farm to fork. In the multiple steps to achieve this, surveillance of animal feed comes as first critical control point for delivering safe animal products. Various factors: biological, chemical, and physical hazards need to be evaluated regarding their impact on animal health and productivity as well consumer safety. Considering the enormous importance of the issue for food safety and human health, further initiative/mission should be initiated by international organizations (FAO/WHO/ OIE) to encourage the creation of a database on the occurrence of undesirable substances in animal feeds and to simultaneously build capacities of stakeholders involved in feed manufacturing/regulation/quality control to control this occurrence.

Advancement in feed safety assessment can be achieved only through multidisciplinary approaches involving agriculture, feed processing and technology, animal nutrition, microbiology, toxicology, veterinary medicine and related disciplines. The United Nation's Millennium Development Goals (MGD's) and Sustainable Development Goals (SDG's), both, realized the importance of environmental sustainability and good health and Safeguarding human health through feeding safe feed to livestock is an important step towards fulfilling those goals and objectives and to attain sustainable food supplies.

\section{References}

Chang, Q.; Wang, W.; Regev-Yochay, G.; Lipsitch, M.; Hanage, W. P. 2014. Antibiotics in agriculture and the risk to human health: how worried should we be? Evolutionary Applications, 8: 240-247.

Clifton, J. C. 2007. Mercury exposure and public health.Pediatr.Clin. North Am. 54: 231-237. 
Crump, J. A.; Griffin, P. M. and Angulo, F. J. 2002.Bacterial contamination of animal feed and its relationship to human foodborne illness. Clinical Infect. Diseases. 35: 859-865.

Czuprynski, C. J. 2005. Listeria monocytogenes: silage, sandwiches and science. Anim. Health Res. Rev. 6: 211-217.

Dorne, J. L. C. Mand Fink-Gremmels, J. 2013. Human \& animal health risk assessment of chemicals in the food chain: comparative aspects and future perspectives. Toxicol. Appl. Pharmac. 270:187-195.

EFSA (European Food Safety Authority), 2015.Scientific statement on the health-based guidance value for dioxins and dioxin-like PCBs. EFSA Journal, 13: 4124-4138.

Fink-Gremmels, J. (eds), 2012. Animal feed contamination: effects on livestock and food safety. Woodhead Publishing Ltd.; Cambridge, UK. Pages: 672

FAO/WHO 2013.Report of the seventh session of the Ad-hoc intergovernmental codex task force on animal feeding. Thirty sixth session, Rome, Italy

Havelaar, A. H.; Kirk, M. D.; Torgerson, P. R.; Gibb, H. J.; Hald, T.; Lake, R.J .; Praet, N.; Bellinger, D. C.; de Silva, N. R.; Gargouri, N.; Speybroeck, N.;
Cawthorne, A.; Mathers, C.; Stein, C.; Angulo, F. J.; Devleesschauwer, B., 2015. World Health Organization Global estimates and regional comparisons of the burden of foodborne disease in 2010.PLoS Med 12: e1001923

Kan, C. and Meijer, G. 2007. The risk of contamination of food with toxic substances present in animal feed. Anim. Feed Sci. Technol. 133: 84108.

Landers, T. F.; Cohen, B.; Wittum, T. E.; Larson, E. L. 2012. A review of antibiotic use in food animals: perspective, policy, and potential. Public Health Rep. 127: 4-22.

Marroquín-Cardona, A. G.; Johnson, N. M.; Phillips, T. D.; Hayes, A. 2014.Mycotoxins in a changing global environment-a review.Food Chem.Toxicol. 69:220-230.

Sharma, V.; Sharma, S.; Datt, C. 2015. Potential hazards in animal feeds: Safety and Regulation - Review. Indian J. Anim. Nutr. 32 (3): 242-262.

Sharma.S.; Sharma.V.; Jain.J.; Agarwal.S.; Dahiya. D. K.; Khan, A. 2016. Organochlorine, organophosphate, synthetic pyrethroids assessment in bovine milk and water samples of Jaipur, Rajasthan, Indian Journal of Animal Sciences 86 (3): 288-293.

\section{How to cite this article:}

Ramchandra Ramteke, M. K. Gendley, Raina Doneria and Jolhe, D. K. 2020. Possible Health Hazard due to Effect of Utilization of Waste as Animal Feed. Int.J.Curr.Microbiol.App.Sci. 9(07): 2102-2108. doi: https://doi.org/10.20546/ijcmas.2020.907.244 